\title{
A MUDANÇA DA POLÍTICA EXTERNA BRASILEIRA PARA IMIGRANTES E REFUGIADOS: O CASO DA IMIGRAÇÃO HAITIANA NO INÍCIO DO SÉCULO XXI
}

\author{
Roberto Rodolfo Georg Uebel \\ Universidade Federal do Rio Grande do Sul - UFRGS - Brasil
}

\section{Resumo}

Devido ao acentuado fluxo migratório de haitianos com destino ao território brasileiro, verificado especialmente após o ano de 2010, o presente artigo analisa a mudança ocorrida na política externa brasileira para imigrantes e refugiados com foco nesse grupo migratório. $\mathrm{O}$ trabalho parte do pressuposto de que ocorreu uma recategorização desses migrantes, anteriormente classificados pelo governo brasileiro como refugiados, frente aos anseios de projeção internacional do país. Tais anseios cristalizaram-se sob a atuação do Brasil nos fóruns regionais sobre a temática de migração e direitos humanos, no comando da Missão das Nações Unidas para a Estabilização no Haiti e com o assento definitivo na Organização Internacional para as Migrações e Alto Comissariado das Nações Unidas para Refugiados, quiçá, um degrau às pretensões do Estado brasileiro junto ao Conselho de Segurança das Nações Unidas. Utilizando-se da abordagem de autores sobre a Política Externa Brasileira contemporânea, vislumbrar-se-á então quais foram as fontes de mudança sofridas na política externa e migratória brasileira, com base no caso do trato dos haitianos, que possivelmente replicam-se para outros grupos destacados, como de sírios e senegaleses. Por fim, o artigo aponta os desafios e pontos de convergência entre estas duas políticas, além das incongruências decorrentes da problemática migratória interna somada aos anseios de inserção estratégica externa do governo brasileiro entre 2010 e 2015.

Palavras-chave: Imigração; Brasil; Política Externa; Haitianos.

\section{Introdução}

Os movimentos migratórios internacionais reassumiram, sobretudo no final dos anos 1980, importância crescente no cenário mundial. Cenário este que, a par das grandes transformações econômicas, sociais, políticas, culturais e ideológicas em curso, tem-se caracterizado por desigualdades regionais acentuadas, pela manifestação crescente de conflitos diversos, bem como pela constituição de mercados integrados como o Tratado Norte-Americano de Livre Comércio (NAFTA), União Europeia, Mercado Comum do Sul (MERCOSUL) e outros (PATARRA, 1995).

Dentro dessa lógica de transformação do cenário mundial, Uebel (2015a) e Arcarazo e Wiesbrock (2015) apontam que o Brasil também se inseriu em uma nova ordem e agenda dos 
fluxos migratórios internacionais, em especial quando considerados os fluxos de haitianos, senegaleses e sírios. Todavia, é necessária uma definição sobre tais fluxos migratórios, compostos por refugiados e imigrantes econômicos.

Os refugiados são considerados migrantes internacionais forçados, que cruzam as fronteiras nacionais de seus países de origem em busca de proteção, fugindo de situações de violência, como conflitos internos, internacionais ou regionais, perseguições em decorrência de regimes políticos repressivos, entre outras violações de direitos humanos. Questões étnicas, culturais e religiosas, desigualdade socioeconômica, altos níveis de pobreza e miséria e, sobretudo, instabilidade política estão no cerne dos fatores que levam às migrações de refugiados $^{1}$ (MOREIRA, 2015).

Já Maria Beatriz da Rocha-Trindade, em sua obra Sociologia das Migrações, apresenta-nos os conceitos básicos de migração, realizando também uma interpretação sociológica sobre a distinção entre imigrantes e emigrantes:

\begin{abstract}
À diferença de designações [imigrantes e emigrantes], atribuídas afinal aos mesmos indivíduos, correspondem também diferentes estatutos sociais: o emigrante é um nacional ausente, com perda pouco significativa de direitos no país de onde provém e, talvez até, uma certa diminuição dos deveres e obrigações inerentes à sua qualidade de cidadão. Em contrapartida, como imigrante, é um estranho vindo de fora, encontrando uma sociedade que provavelmente desconhece e onde terá de inserir-se, sujeitando-se às leis que a administram. (ROCHA-TRINDADE, 1995, p. $31)$.
\end{abstract}

Nota-se, com a interpretação sociológica da autora um viés jurídico sobre a situação dos cidadãos que migram internacionalmente. Emigrar significa, portanto, deixar o Estadonação ou a própria terra para se refugiar, trabalhar temporariamente ou estabelecer residência em um país distinto; os protagonistas dessa ação são designados, por quem os considere como ausentes e enquanto essa situação se mantiver, como emigrantes.

Ao atingir o território de outro Estado para solicitar refúgio ou autorização de trabalho, tais migrantes se deparam com políticas estatais que podem lhes ser mais benéficas ou restritivas. Diversos fatores pesam na política relativa a refugiados (refugee policy) adotada por um país. O peso da política externa (foreign policy) sobre as decisões estatais frente aos refugiados ganha destaque à medida que esses deslocamentos se originam de situações de instabilidade política interna que geram repercussões internacionais.

\footnotetext{
${ }^{1}$ De acordo com a Convenção de 1951, relativa ao Estatuto dos Refugiados, são refugiados aqueles que se encontram fora do seu país por causa de fundado temor de perseguição por motivos de raça, religião, nacionalidade, opinião política ou participação em grupos sociais, e que não podem (ou não querem) voltar para casa. Posteriormente, definições mais amplas passaram a considerar como refugiadas as pessoas obrigadas a deixarem seu país devido a conflitos armados, violência generalizada e violação massiva dos direitos humanos.

Barbarói, Santa Cruz do Sul, Edição Especial n.47, p.<22-43>, jan./jun. 2016
} 
Os interesses relacionados à política externa guiam as respostas aos fluxos por parte dos países receptores, de maneira que a admissão de refugiados pode servir como estratégia para desacreditar Estados-nação adversários. Com isso, o reconhecimento do estatuto e a recepção de refugiados podem ficar condicionados aos países dos quais eles provêm, sendo considerados bem-vindos em virtude da afinidade político-ideológica. Dentre os interesses de política externa, são computados, portanto, elementos estratégicos, políticos, ideológicos e de segurança (TEITELBAUM, 1984; LOESCHER, 1996).

A influência internacional sobre a política relacionada aos refugiados também pode ser percebida em outros aspectos. Tal política pode ser concebida como uma oportunidade para Estados que pretendem superar suas experiências passadas, restaurando sua reputação, a fim de obter legitimidade por parte de seus vizinhos e da comunidade internacional. Quanto a Estados que fazem parte de regiões propícias a gerar fluxos de refugiados, esses países tendem a desenvolver uma política mais abrangente, com o intuito de ajudar a reduzir os deslocamentos no âmbito regional (ZOLBERG; SUHRKE; AGUAYO, 1996).

Vale destacar ainda o impacto dos regimes internacionais nas respostas políticas dadas aos deslocamentos, uma vez que os países pretendem projetar uma imagem positiva internacional, de modo a serem vistos como generosos em questões humanitárias, como bem coloca Valler Filho (2007) para o caso brasileiro, sobre a solidariedade interposta na sua ação por meio da Missão das Nações Unidas para a Estabilização no Haiti (MINUSTAH). A necessidade de assistência e a tentativa de evitar a publicidade negativa levam o país acolhedor a interagir com o regime internacional, que, por sua vez, pressiona o governo a implementar medidas que beneficiem os refugiados (JACOBSEN, 1996).

Política em relação aos migrantes intersecta, portanto, fatores de política externa com política doméstica. Resulta de uma interação complexa entre interesses domésticos econômicos, socioculturais, políticos, ideológicos, demográficos, além de questões internacionais, relacionadas com política externa, regimes e organizações internacionais. Ainda está relacionada, por fim, à interação com atores internacionais (especialmente com o ACNUR - Alto Comissariado das Nações Unidas para Refugiados e OIM - Organização Internacional para as Migrações) e de atuação doméstica (como ONGs, instituições religiosas e da sociedade civil, diretamente envolvidas com a assistência a refugiados), conforme se abordará nas seções a seguir com foco especial ao caso dos haitianos.

Nesse sentido, este artigo problematiza a seguinte questão: quais foram os redirecionamentos da política migratória brasileira recente vis-à-vis ao 1) aumento do fluxo de haitianos e suas consequências e 2) aos anseios da inserção estratégica brasileira? Essas Barbarói, Santa Cruz do Sul, Edição Especial n.47, p.<22-43>, jan./jun. 2016 
questões apresentam-se à luz da hipótese de que a política externa brasileira para imigrantes e refugiados sofreu um redirecionamento - com base no caso dos haitianos - em virtude do aumento dos fluxos de migrantes internacionais para o país em combinação com os anseios de projeção internacional do próprio Brasil e seu governo, sem olvidar também aspectos securitários e de diplomacia na perspectiva da PEB.

Para esta análise, apresentaremos na primeira seção do texto um panorama da imigração haitiana recente para o Brasil (a partir de 2010), expondo suas rotas e motivações principais, além de uma estimativa de quantificação. Na segunda seção do texto, trataremos sobre a política externa combinada com a política migratória específica aplicada aos haitianos por parte do governo brasileiro, abrindo o debate para a terceira e última seção, onde abordaremos quais foram as fontes de mudança e os estágios sofridos na política externa brasileira para migrantes, com base no caso do trato aos haitianos, que possivelmente replicam-se também no caso da reclassificação - oriunda da reorientação da política externa dos sírios e migrantes da costa oeste africana, conforme bem coloca a literatura contemporânea (REDIN; MINCHOLA, 2015).

A fim de colaborar com a argumentação teórica do texto, faz-se igualmente uso da abordagem dos jogos de dois níveis enunciados por Putnam (2010), ao passo em que fatores externos, segundo a hipótese do texto, em consonância com pressões internas de alavancagem para fora, teriam influenciado o redirecionamento da política externa brasileira para migrantes e refugiados, em especial por meio desse caso dos haitianos, o que se discutirá nos resultados e conclusões finais deste artigo. Logo, o texto encerra com essas considerações finais e apontamentos de rumos da questão imigratória dentro da política externa brasileira e sua formulação.

\section{A imigração haitiana para o Brasil}

A migração de haitianos ganhou destaque nas estatísticas e na imprensa brasileira muito recentemente (2010-2014). Tal situação se deu após a crise econômica internacional aliada à guerra civil e crise humanitária no Haiti bem como a instabilidade econômica e política do país. Soma-se a isto ainda a atratividade econômica e laboral verificada pelo Brasil e, em especial, pelo Rio Grande do Sul no mesmo período, estado que será destacado nesta seção, dada a forte presença desta comunidade imigratória em seu território e onde mais observou-se a efetividade das políticas públicas oriundas da política externa brasileira para imigrantes e refugiados. 
Todavia, Uebel (2015b) ao analisar os dados estatísticos e documentos cartográficos de representatividade desse grupo imigratório, tanto no Brasil como no Rio Grande do Sul, chegou ao seguinte ranking para o biênio 2013-2014: os haitianos estão em $16^{\circ}$ lugar dos maiores grupos imigratórios no Brasil; no Rio Grande do Sul, enquadram-se como terceiro maior grupo imigratório.

Posto isso, apesar de sua notoriedade - aparentemente midiática e sensacionalista - tal grupo não representa - à exceção do Rio Grande do Sul - somas elevadas e consideráveis de indivíduos, se comparados a outros grupos recentes, como os sírios, bolivianos e chineses, por exemplo. Ressalta-se, além disso, que tais fluxos são partícipes do boom imigratório verificado tanto nesse estado como no Brasil em 2010 e em 2013-2014 (SILVA, 2015).

Segundo os dados oficiais compilados por Uebel (2015a), havia até o mês de outubro de 2014, 27.970 imigrantes de origem haitiana - embora os dados não oficiais apontassem uma estimativa de 50 mil imigrantes - majoritariamente chegados após um longo processo de migrações e rotas internas no Brasil, que estão apresentadas no Mapa 1:

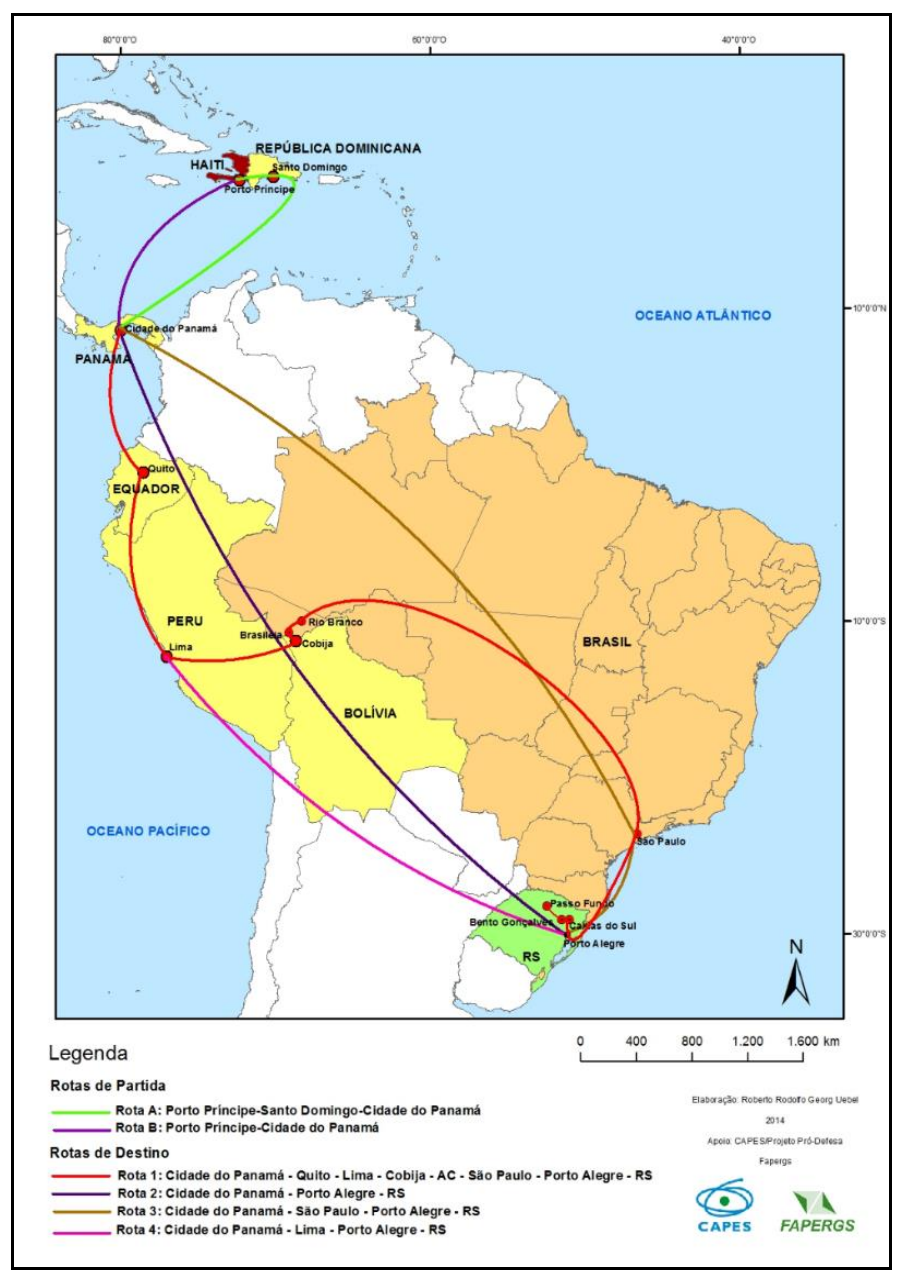

Mapa 1 - Rota dos imigrantes haitianos em direção ao Rio Grande do Sul.

Fonte: Elaborado pelo autor. 
Considerando isso, observa-se que as quatro rotas de imigração dos haitianos são constituídas de redes de contatos e informações, distribuídas no que concluímos ser gerações de imigrantes em um curto período de tempo, isto é, a primeira geração dos imigrantes haitianos, após a crise humanitária e terremoto de 2010, era predominantemente constituída de homens, solteiros e pais de família desacompanhados, que vislumbravam apenas a chegada ao Brasil e inserção no mercado laboral.

Já a segunda geração possuía um caráter distinto da primeira, ao passo em que estabelecidas as redes com os primeiros emigrados, retoma após 2013 um forte fluxo já destinado aos estados da Região Sul do Brasil, daí incluindo-se mulheres, imigrantes mais velhos, famílias completas com crianças e com graus de instrução mais variados.

Desse modo, a motivação que levou a essas duas gerações de imigrantes, seguindo-se os preceitos de Piore (1979), é a mesma: melhores condições laborais - ou seja, salariais - e possibilidade de construção de um projeto de vida familiar no Brasil, já que não há perspectivas de retomada do crescimento do Haiti no médio e mesmo no longo prazo. O que as diferencia são suas caracterizações demográfico-sociais, rotas e forma como são atraídas, além de que a segunda geração apenas emigrou por causa de uma rede já estabelecida pela primeira geração e facilitada pela reorientação da política migratória brasileira de concessão de vistos humanitários, ao invés de refúgio, permitindo, assim, a emissão imediata das autorizações de trabalho.

Quanto à concessão de vistos humanitários em detrimento do status de refugiado, a problematização que levou a essa tomada de decisão por parte do governo brasileiro deu-se em virtude de todas as obrigações do Estado para com aquele que recebe a proteção do refúgio, tais como garantias civis, sociais, educacionais e até mesmo trabalhistas.

Em um cenário crescente e de boom imigratório, como no caso dos haitianos em direção ao Brasil, e não verificadas as condições requerentes para a concessão do refúgio a esses migrantes, principalmente de perseguição política, o governo Brasileiro decidiu, por sugestão do próprio Alto Comissariado das Nações Unidas para Refugiados (ACNUR) e da Organização das Nações Unidas, conceder um visto humanitário aos haitianos, não onerando o governo brasileiro das obrigações da Convenção de Genebra, mas permitindo a agência desses migrantes no território brasileiro com uma proteção estatal mínima. Autores como Leal e Leite (2012) advogam ainda que os haitianos poderiam ser considerados refugiados ambientais, uma nova categoria de refúgio, altamente debatida pelos meios acadêmicos e jurisprudenciais na contemporaneidade. 
Segundo as discussões realizadas no âmbito da $1^{\text {a }}$ COMIGRAR e de próprios estudos recentes da Organização Internacional para as Migrações (2009), o fator principal que levou ao ato de emigrar para o Brasil destes indivíduos foi a atuação estratégica brasileira no Haiti capitaneada pelas ações da Missão das Nações Unidas para a estabilização no Haiti (MINUSTAH), gerida pelas próprias forças brasileiras. Sobre a MINUSTAH, o Ministério das Relações Exteriores do Brasil assim a caracteriza:

\begin{abstract}
"A convite das Nações Unidas, desde 2004 o Brasil exerce o comando militar da Missão de Estabilização das Nações Unidas no Haiti (MINUSTAH) - atualmente comandada pelo General José Luiz Jaborandy Junior. Trata-se da missão mais latino-americana da história da $\mathrm{ONU}$, contando com a participação de 13 países dessa região. O Brasil é o principal contribuinte de tropas, com cerca de 1.430 militares e 10 policiais no terreno. [...] Além de contribuir militarmente à MINUSTAH, o Brasil tem buscado intensificar a cooperação técnica e humanitária com o Haiti, com vistas ao desenvolvimento do país. A Companhia de Engenharia Militar brasileira tem participado nesse esforço, desempenhando atividades como perfuração de poços artesianos, construção de pontes e açudes, contenção de encostas, construção e reparação de estradas - além de atuar em missões de defesa civil, sobretudo após o terremoto de 2010. [...] O empoderamento e a capacitação das instituições haitianas são fundamentais para que a redução e a eventual retirada da missão ocorram sem maiores sobressaltos e perda dos esforços já desenvolvidos para reerguer o país. O Brasil mantém firme compromisso com a estabilidade, com a segurança e com o desenvolvimento do Haiti." (MINISTÉRIO DAS RELAÇÕES EXTERIORES, 2016)
\end{abstract}

Assim, a presença maciça brasileira em território haitiano, somada às propagandas positivas do país pelos peacekeepers e outras motivações de ínterim pessoal, bem como crescimento atrativo do mercado de trabalho e economia brasileira, além de ser um país mais fácil de imigrar do que outros vizinhos, como Estados Unidos e Canadá, conjugaram em um uma motivação única que obteve como consequência este boom imigratório de haitianos no Brasil.

\title{
A política externa brasileira para migrantes: o caso dos haitianos
}

Com uma postura contrária à de países do Hemisfério Norte - especialmente Estados Unidos, Reino Unido e membros da União Europeia - que, por motivos de ordem econômica, social e até mesmo cultural (RÜCKERT, 2015), tencionam fechar suas fronteiras para imigrantes e refugiados, como percebe-se especialmente com as migrações de centroamericanos para os Estados Unidos e norte-africanos, sírios e europeus do leste para o Reino Unido e União Europeia, o Brasil tem-se mostrado mais flexível em adotar uma política próestrangeiro, embora ainda utilize como base legal o Estatuto do Estrangeiro do período ditatorial, em contraposição às contemporâneas e elogiadas normativas do Comitê Nacional 
para Refugiados. Todavia, como coloca Cervo (2008), trata-se de um processo de mudança pelo qual passa a política externa brasileira, com a assimilação de novos conceitos e práticas, inclusive aquelas relacionadas à recepção de estrangeiros.

Para Reis (2011), o tratamento dado à questão migratória pelo Estado brasileiro está relacionado não apenas ao importante ativismo de migrantes e seus aliados, mas também

\footnotetext{
"[...] tem relação direta com o objetivo de defender e assegurar o protagonismo do país em fóruns regionais e multilaterais, dentro de um contexto internacional em que o tema é cada vez mais importante e controverso. Nesse sentido, podemos caracterizar a política em relação aos emigrantes, e também aquelas de cunho regional, como formas de política externa. Nos últimos anos, mesmo a política de imigração começou a ser percebida como parte importante da posição do Brasil em relação às migrações no plano internacional, o que explica as mudanças que estão sendo propostas no sentido de tornar mais coerente a posição do país em relação às migrações no sentido mais amplo. ” (REIS, 2011, p. 49)
}

No governo de Luiz Inácio Lula da Silva (2003-2006 e 2007-2010), a política externa passou por ajustes de programa, configurando uma "mudança na continuidade" seguindo o entendimento de Vigevani e Cepaluni (2007). As alterações significativas estavam mais relacionadas à ênfase e aos meios buscados para inserção do país no cenário internacional do que propriamente ao conteúdo dos objetivos perseguidos (SOUZA, 2009).

A principal modificação consistiu em diversificar as opções adotadas, compondo uma estratégia denominada de autonomia pela diversificação. As diretrizes de política externa mantiveram, assim, o multilateralismo, a cooperação, a defesa dos direitos humanos, a construção da paz, a adesão aos regimes, o respeito às organizações internacionais e a priorização aos países da região, especialmente do MERCOSUL (VIGEVANI; CEPALUNI, 2007).

Ademais, a cooperação Sul-Sul também foi enfatizada, a partir da aproximação com países em desenvolvimento e emergentes, a fim de obter vantagens políticas e econômicas, como bem coloca Burges (2013). A formação do G20, com o objetivo de liberalizar o comércio agrícola e, com isso, buscar reduzir assimetrias entre os países, e a atuação brasileira frente à coalizão foram emblemáticas. A instituição do fórum IBAS, em parceria com Índia e África do Sul, também apontava nesse sentido. Ainda se acentuaram aspirações em torno da reforma do Conselho de Segurança da ONU, empreendendo-se maiores esforços para tanto, a exemplo da atuação humanitária com envio de missão brasileira para operação de paz no Haiti (VIGEVANI; CEPALUNI, 2007).

A liderança regional (ou a intenção objetiva de exercê-la, dada a contestação existente nos meios acadêmicos e inclusive diplomáticos sobre essa questão) passou a ser exercida de Barbarói, Santa Cruz do Sul, Edição Especial n.47, p.<22-43>, jan./jun. 2016 
forma mais assertiva, embora sem adotar uma postura ostensiva ou confrontadora. Em paralelo, a América Latina seguiu sendo tratada como prioridade. O país assumiu a posição de intenção de administrar as crises humanitárias e arbitrar os conflitos políticos na região, com vistas a assegurar a estabilidade regional (VIGEVANI, CEPALUNI, 2007; RODRIGUES, 2010). A atuação no Haiti, liderada pelo Brasil, também pode ser associada ao desempenho dessa função, bem como um exemplo desta cooperação Sul-Sul.

A pretensão de conquistar maior protagonismo global ganhou peso. $\mathrm{O}$ país passou a ser considerado como uma economia emergente e pretendia, assim, obter um espaço maior nas decisões tomadas no cenário mundial. A inserção do Brasil no bloco dos BRICS também propiciava maior participação brasileira no processo decisório internacional (LIMA; HIRST, 2006; RODRIGUES, 2010), que envolvia, dentre as diversas agendas, o protagonismo dos países do bloco na agenda das migrações (KOROBKOV, 2015).

O governo Lula manteve a ênfase no tema dos direitos humanos, não só como diretriz de política externa, mas também como pauta da agenda interna. Novos órgãos foram criados no âmbito da Secretaria Especial de Direitos Humanos, que passou a ser vinculada à Presidência da República. Houve continuidade na elaboração do Programa Nacional de Direitos Humanos, com lançamento do terceiro projeto no final do segundo mandato (III PNDH).

Lula da Silva também continuou a investir no tema dos refugiados, que havia sido tratado como política governamental no período anterior (governo de Fernando Henrique Cardoso - 1995-2002). O papel de liderança brasileira frente à América do Sul em matéria de refugiados também passou a ser reconhecido pelo ACNUR: "O Brasil se tornou o líder regional com a aprovação da lei sobre refugiados em 1997” (ACNUR, 2003, p. 8 apud JUBILUT, 2006, p. 1). No discurso proferido na $60^{\mathrm{a}}$ sessão do Comitê Executivo do ACNUR, a delegação brasileira afirmava que:

O refúgio é uma política de Estado no Brasil. É um elemento importante da democracia brasileira e sua tradição de abertura. É um dos pilares da política de direitos humanos. [...] Nós esperamos aumentar as oportunidades de reassentamento no Brasil. A longa experiência do Brasil em ter um órgão tripartite em que governo, sociedade civil e ACNUR trabalham juntos em políticas para refugiados tem sido bem-sucedida. [...] O processo de integração social e econômica dos refugiados tem sido um constante desafio. Acreditamos que o engajamento de outros países em programas de reassentamento abre as portas para cooperação sul-sul. O Brasil está pronto a compartilhar sua experiência com parceiros interessados (MOREIRA, 2015, p. 5-6). 
A política relacionada aos refugiados havia sido estruturada, no período anterior, com base em componentes políticos domésticos e externos, fundada nos direitos humanos e articulada a partir de atores estatais e não estatais (governo - destacando-se o estabelecimento do CONARE - Comitê Nacional para Refugiados, organização internacional - ACNUR - e instituições da sociedade civil - com a Cáritas Arquidiocesana). Além da posição de país emergente, a busca por maior protagonismo global, a liderança regional, a atuação em defesa dos direitos humanos e a cooperação no eixo Sul-Sul apontavam que o tema dos refugiados não deixaria de fazer parte da agenda política brasileira no governo Lula (RODRIGUES, 2010).

Ainda no governo Lula da Silva e, atualmente, na gestão de Dilma Rousseff (20112014 e 2015 até o presente), buscou-se conquistar uma posição mais relevante para o Brasil no cenário internacional, afim de ocupar maior importância política participando ativamente de organismos internacionais e missões humanitárias (SARAIVA, 2014). Para o Brasil, ter tropas atuando no Haiti é uma forma de atingir seus objetivos diplomáticos, estando, dentre eles, a possibilidade de ocupar um assento permanente no Conselho de Segurança das Nações Unidas (ONU) (LEAL; LEITE, 2012).

Esforços foram perpetrados no sentido de consolidar o papel relevante do país, cuja presença no Haiti faz parte dos métodos para se atingir esse objetivo, e a sua eleição, em 2010, como membro não permanente do Conselho de Segurança por dois anos, representou os resultados positivos obtidos até então. Desse modo, a vinda de deslocados haitianos para o Brasil foi consequência de sua ativa participação na estabilidade do país por meio da operação MINUSTAH, conforme citado na seção anterior. Todavia, não houve planejamento para acolher esses deslocados que chegavam em dezenas todos os dias ao Brasil.

A primeira providência do governo brasileiro foi conceder cem vistos humanitários mensais para regularizar a situação desses deslocados. Contudo, foi uma atitude considerada equivocada posteriormente, uma vez que se criou uma cota de concessão além dos padrões normais, ou seja, uma ampliação de direito que o país não poderia suportar à época. A consequência imediata foi que dezenas de haitianos, desesperadamente, candidataram-se ao visto, gerando instabilidades locais - como no caso da superlotação dos abrigos na fronteira brasileira com a Bolívia no estado do Acre - e o receio do governo brasileiro em ter que voltar atrás com a medida.

Ao conceder os cem vistos mensais, o Brasil tentava absorver os deslocados que eram vítimas dos chamados "coiotes", que recebiam dinheiro para atravessar os haitianos pela floresta e conseguirem ingressar, de forma irregular, no território brasileiro. 
Em sequência, o governo brasileiro aprovou uma revisão da política migratória para haitianos no Brasil. Foi publicada no Diário Oficial, em 29 de abril de 2013, a resolução $n^{\circ} 102 / 2013$ do Conselho Nacional de Imigração (CNIg), determinando o fim do limite máximo de 1200 vistos anuais e da exclusividade da Embaixada Brasileira em Porto Príncipe em concedê-los.

Dois pontos precisam, então, ser destacados no quadro de políticas migratórias brasileiras com a questão haitiana: o não reconhecimento do status de refugiado e a implementação dos vistos de permanência especiais a haitianos por razões humanitárias. Analisaremos essas medidas enquanto dispositivos de políticas migratórias combinados com a política externa brasileira, de acordo com o já ilustrado, na seção a seguir.

\section{Mudanças da política imigratória: uma combinação com a política externa e direitos humanos}

A chegada dos primeiros haitianos, e o crescente fluxo, criou a necessidade de um posicionamento estratégico do governo brasileiro que, de fato, tomou posição: a de não concessão do status de refugiado aos haitianos, alegando não poder admitir desastres naturais como bem-fundado temor de perseguição, nem enquanto vítimas das consequências desses desastres, apesar das definições citadas no início do texto em menção à Convenção de Genebra. Mais ainda, ressalta-se que o próprio sucesso da MINUSTAH - em especial quando observada a posição do Itamaraty sobre isto, colocada na primeira seção - preconizaria uma situação de não-perseguição ou de não-violação aos direitos humanos no Haiti, mas sim de uma migração com motivações estritamente econômicas e laborais, nos moldes clássicos apontados por Rocha-Trindade (1995).

Muito se ventilou também acerca da possibilidade de conceder refúgio através da Declaração de Cartagena de 1984, que prevê a situação de massiva violação aos direitos humanos, uma vez que a situação do Haiti pós-terremoto não permitia a satisfação dos mais básicos direitos humanos, conforme aponta Santos (2014) em seu trabalho.

A negação sumária dos pedidos de refúgio de haitianos no Brasil, ou seja, automaticamente encaminhadas para o CNIg, depõe, como sugere Jubilut (2007), contra o argumento de segurança nacional e conta a própria atuação do Brasil dentro da MINUSTAH, posto que possuía poder de política e pacificação no Haiti, logo, compreendendo como uma agente ao lado do Estado haitiano.

Isso entra em convergência com a própria análise do pedido de refúgio pelo Comitê Nacional para Refugiados (CONARE), onde há a verificação de antecedentes criminais mais Barbarói, Santa Cruz do Sul, Edição Especial n.47, p.<22-43>, jan./jun. 2016 
aprofundada, de acordo com a lei 9.474/1997 que emana os princípios da Convenção de 1951 sobre refugiados (JUBILUT, 2007). Os vistos humanitários são vistos especiais emitidos mais rapidamente, num processo de fast track, ou seja, de modo mais rápido que o normal, neste caso, bastando a apresentação da documentação e a verificação de sua autenticidade, dispensando análises protocolares mais profundas (SICILIANO, 2013).

É interessante observar que o fechamento da fronteira foi utilizado num momento que o governo julgou crítico, um ato estratégico para tentar conter a entrada dos haitianos - muito embora não tenha surtido o efeito desejado (FERNANDES et al., 2013; VENTURA; ILLES, 2012). Por conseguinte, fechando as fronteiras, o governo brasileiro teve uma postura objetiva e material de barrar a entrada de migrantes provenientes do Haiti.

Dessa forma, fazendo-o, o Brasil passou a mensagem de que haitianos não seriam bem-vindos, tanto para os próprios imigrantes, quanto para a própria população brasileira; ato que reforça os dizeres de Póvoa Neto (2008) acerca do processo que liga o imigrante haitiano à ideia do indesejável e àquele que traz males sociais. As forças políticas contrárias à vinda dos haitianos começaram, então, crescentemente, a propagar visões negativas via grande mídia a partir de 2011, intensificando nos anos vindouros, como atesta Santos (2014) em sua pesquisa.

Fechada a possibilidade para concessão de refúgio, criou-se uma via intermediária que reconhecia a situação sui generis dos haitianos no Brasil, sem conceder refúgio, mas diferenciando-os frente a outros imigrantes. $\mathrm{O}$ instrumento normativo que regulava essa possibilidade impunha barreiras e medidas de controle tão estritas quanto as pontes: a Resolução Normativa 97/2012 do CNIg impunha controle geográfico e quantitativo da emissão dos vistos especiais (BRASIL, CNIg, 2012).

O caso de cotas já teria sido utilizado no Brasil em 1930 e 1934, visando evitar situações de grave ameaça social, porém, a utilização de cotas no caso dos haitianos somente denunciava a falta gestão das imigrações no Brasil (SICILIANO, 2013). Conforme Póvoa Neto (2008), podemos analisar que os 1200 vistos humanitários previstos pela resolução seria uma tentativa de controlar o fluxo de haitianos, impedindo e jogando à marginalidade a demanda que excedesse esse número e, ainda assim, viesse ao Brasil. Mais uma vez, a parte objetiva do dispositivo carrega implicações fortemente subjetivas que podem dar margem à xenofobia, especificamente aos haitianos e contrariando os princípios da política de inserção estratégica do Brasil defendida à época.

Dentre esses princípios - que se verificaram ativamente até o afastamento da presidente Dilma Rousseff em maio de 2016 -, vislumbrava-se a atuação brasileira como Barbarói, Santa Cruz do Sul, Edição Especial n.47, p.<22-43>, jan./jun. 2016 
ativa, intermediadora de conflitos e promotora da integração regional latino-americana, sem olvidar a própria questão da mobilidade de trabalhadores, logo, de migrantes, no âmbito da UNASUL $^{2}$ como uma das propostas dos grupos de trabalho liderados pelo Brasil, não apenas nessa organização, mas também em conjunção com fóruns da América Central, Caribe e países andinos.

Entretanto, essa postura e atitudes mostram-se diferentes dos argumentos de solidariedade e zelo pelos direitos humanos dos haitianos imigrantes em direção ao Brasil, quando da publicação da RN 97/2012. Ademais, o Peru passou a exigir visto dos haitianos somente na metade de 2012, por pressão do Brasil (CHADE, 2012), além de influenciar outras nações vizinhas a endurecerem seu controle migratório, como Bolívia e Paraguai, também por pressão de Brasília, revelando a forte influência do país nas decisões da agenda migratória sul-americana.

Apesar da tentativa brasileira de mudar a postura também do Equador, país-referência nas políticas de migração e refúgio, não houve mudança nas exigências para a entrada de haitianos naquele país (CHADE, 2012), já que o governo equatoriano mantém uma postura de abertura e recepção a estrangeiros de forma ímpar no Sistema Internacional, tradição que perdura nas últimas décadas sem alterações. É válido ilustrar também uma dissociação entre a pressão exercida pelo Ministério da Justiça e aquela pelo Serviço Exterior do Brasil, que muitas vezes não dialogam ou não possuem convergências de posições em temas específicos, como neste das migrações de haitianos.

Portanto, trata-se de uma atitude muito ilustrativa que mostra o real intuito desse dispositivo de política migratória, que é constituído por instrumentos jurídicos limitantes, bloqueio de fronteira em certos momentos; forças políticas promovendo um recorte do saber através de discursos midiáticos negativos; pressão diplomática em países vizinhos para dificultar a chegada dos haitianos.

Com a revogação do limite de vistos a partir de 2013, abriram-se novas oportunidades nos postos diplomáticos do Brasil no exterior, em especial nos de Porto Príncipe e Santo Domingo, para a solicitação do visto humanitário para haitianos, normalmente concedido; porém, o refúgio - o status de refugiados - continuou a ser negado nessa nova política externa combinada com política imigratória.

\footnotetext{
${ }^{2}$ É de proposição brasileira a inclusão do artigo 11 dos objetivos específicos da UNASUL, que trata justamente sobre a cooperação e integração por meio das migrações: "La cooperación en materia de migración, con un enfoque integral, bajo el respeto irrestricto de los derechos humanos y laborales para la regularización migratoria y la armonización de políticas." (UNIÃO DE NAÇÕES SUL-AMERICANAS, 2008).

Barbarói, Santa Cruz do Sul, Edição Especial n.47, p.<22-43>, jan./jun. 2016
} 
Por três anos, os vistos humanitários se constituíram como a resposta estratégica do governo brasileiro frente à chegada dos haitianos, que começou em 2010. A ruptura desta continuidade surgiu apenas em novembro de 2015, quando o governo brasileiro concedeu a autorização permanente para 43.781 imigrantes haitianos, que entraram no Brasil pela fronteira terrestre com o Acre, a partir de 2010, e não se enquadram na condição de refugiados, conforme as palavras do então Ministro da Justiça, José Eduardo Cardozo:

Essa autorização de permanência é muito importante porque ela supera a fase do
visto provisorio e dá uma perspectiva definitiva para que eles possam aqui residir
utilizando e fazendo jus de todos os direitos que um estrangeiro tem no Brasil. Eles
passam a ter novas oportunidades de trabalho, inserção social e participação em
programas sociais. É um reconhecimento muito claro de que o Brasil é um país que
acolhe seus imigrantes, que respeita direitos e não age de forma preconceituosa.
(AGÊNCIA BRASIL, 2015).

Essa mudança se deve fundamentalmente a dois fatores: 1) busca pela formalização e integração dos haitianos à sociedade, portando uma autorização permanente que garantirá uma gama maior de direitos - mas também de obrigações - junto ao Estado brasileiro, especialmente no que se refere a inserção no mercado de trabalho, inclusão escolar e universitária, acesso à documentação antes restrita, etc.; 2) necessidade de regularização desses migrantes, possibilitando sua naturalização no futuro, a fim de equipará-los aos nacionais em todas as competências e instâncias do Estado brasileiro, especialmente se observado que muitos trouxeram suas famílias ou passaram a constituir um núcleo familiar no Brasil, já com filhos brasileiros natos.

No intuito de mostrar como a política migratória brasileira evoluiu mais por medidas esparsas do que pela consolidação e modernização da sua lei de imigrantes, o Estatuto do Estrangeiro, lei 6.815 de 1980, tinha como ponto forte a securitização do tema migrações (SICILIANO, 2013; VENTURA; ILLES, 2012). Segundo Siciliano (2013), a proposição legislativa 5.655 de 2009 pretendia congregar os atos isolados em matéria de migração, porém, continuava sem oferecer uma dinamização e respeito aos direitos humanos dos imigrantes em seus artigos.

Assim, temos uma comissão de especialistas que criou e publicou em julho de 2014 um anteprojeto da Lei de Migrações e Promoção dos Direitos Humanos dos Migrantes no Brasil (VENTURA, 2014), com forte participação de atores do Itamaraty. Tal anteprojeto previa, entre outras coisas, a criação da Autoridade Nacional Migratória - ANM, órgão autárquico competente para tratar do tema no Brasil, bem como a do Conselho Nacional de 
Migração - CNM, órgão de articulação e supervisão da aplicação das políticas migratórias composto por representantes do governo e da sociedade civil (VENTURA, 2014).

Não esqueçamos, contudo, que se o Brasil não reconhecia refúgio aos haitianos, sinalizando com o visto humanitário certo reconhecimento da situação haitiana insuficiente para tal, por outro lado, conferia total anuência de calamidade dos direitos humanos participando como chefe da parte militar da MINUSTAH desde 2004 (REDIN; MICHOLA, 2015). Tal fato revela discrepância entre a política externa da solidariedade de Seitenfus ([20-]) aos haitianos no seu país natal e o tratamento dado a estes quando chegam ao território brasileiro. $^{3}$

Com a revogação das cotas e novas possibilidades de obter os vistos humanitários, vigendo até o início de 2015, temos a consolidação do dispositivo migratório brasileiro para os haitianos. Porém, Faria (2015) conclui com ressalvas:

\begin{abstract}
O caso haitiano evidenciou dois aspectos relevantes do debate doméstico em curso sobre a revisão do Estatuto do Estrangeiro: i) a dispersão de responsabilidades e as diferentes nuances dos atores governamentais envolvidos com o tema migratório quanto à dimensão dos direitos humanos na política migratória; e ii) a inexistência de uma política migratória consolidada e abrangente no país, que possa responder de forma sustentável às demandas contemporâneas decorrentes do maior papel desempenhado pelo Brasil como país de destino de migrantes. Por essas duas razões, a resposta ao influxo de haitianos foi estabelecida, como demonstrado, por meio de reuniões emergenciais, que, em larga medida, atenderam às demandas de forma reativa. A fragmentação da política migratória é considerada por alguns setores nacionais como determinante da ação ministerial, por impedir forma de gerenciamento temático que dê conta dos desafios apresentados ao Brasil na condição de país de destino. (FARIA, 2015, p. 92).
\end{abstract}

Mesmo esta pesquisa se concentrando no período histórico 2010-2015, podemos averiguar que o Brasil procurou uma otimização da gestão da migração, tentando conciliar sua agenda interna com os anseios de projeção externa, ainda que muitos desafios na seara institucional e legal impeçam uma consolidação de uma política migratória aliada aos pontos da política externa brasileira.

\footnotetext{
${ }^{3}$ Conforme citado ao longo do texto, a MINUSTAH, comandada pelo Brasil, tinha dentre suas funções pacificar o território e a sociedade haitiana, trazendo elementos de polícia, reestruturação social e civil, organização política, proteção aos direitos humanos e criação - em conjunto com as demais forças, entidades, organizações e com o próprio Estado haitiano - das bases e estruturas para alavancagem do Haiti após a guerra civil e, especialmente, após o terremoto de 2010 que destruiu o país em todas as searas. O que se argumenta aqui é que este mesmo Estado brasileiro teve uma posição distinta quando da recepção dos imigrantes haitianos em seu território desde o começo sem saber como categorizá-los e com dificuldade de alojá-los e encaminhá-los à proteção social e ao próprio mercado de trabalho. Não se intenciona questionar a possível omissão por parte do governo brasileiro, proposital ou não, mas sim o contraste na forma de tratamento aos haitianos em situações de vulnerabilidade semelhante, porém, em circunstâncias e territórios distintos, por parte do mesmo agente, o Estado brasileiro e seus atores institucionais.
}

Barbarói, Santa Cruz do Sul, Edição Especial n.47, p.<22-43>, jan./jun. 2016 


\section{Considerações finais}

A partir das análises sobre os pontos de convergência e distanciamento entre as políticas externa e migratória, foi possível identificar algumas vantagens e desvantagens da coordenação dessas políticas com potenciais impactos para a imagem do Brasil e o fortalecimento do soft power brasileiro.

Por mais que as manifestações protocolares indiquem que o Brasil reconhece o valor dos imigrantes que contribuíram e contribuem para o desenvolvimento do País, isso não significa que deixem de ser aplicadas as sanções previstas na Lei $n^{\circ} 6.815$, de 1980, nos casos de entrada e permanência irregulares, sancionadas com as deportações. Embora o número tenha sido relativamente pequeno no período de 1995 a 2010 (3.203 deportações, média de 200 pessoas/ano), algumas nacionalidades se sobressaem, tais como bolivianos (696 ou 21,7\% do total), peruanos (339 ou 10,6\% do total), chineses (199 ou 6,2\%) e libaneses (175 ou $5,5 \%)$.

O tema dos refugiados também pode ser apontado como um dos fatores que articulam política externa e política migratória. Conforme referido anteriormente, o Brasil é signatário dos principais tratados internacionais de direitos humanos e é parte da Convenção das Nações Unidas de 1951 sobre o Estatuto dos Refugiados e do seu Protocolo de 1967. Em 1997, foi promulgada a Lei $\mathrm{n}^{\circ}$ 9.474, de 1997, a qual contempla os principais instrumentos regionais e internacionais sobre o tema (DIZNER, 2015).

Os focos de desarticulação entre a política externa e a política migratória podem ser identificados em algumas instâncias decisórias que ainda se mantêm resistentes às necessárias adaptações do Estado e da sociedade para fazer frente aos desafios impostos pelo fenômeno migratório. Nesse sentido, durante o período estudado, houve momentos em que as ações de política externa não tiveram impacto sobre a política migratória, tiveram impacto muito reduzido ou seus efeitos levaram muito tempo para se manifestar. Essa desarticulação pode ser indicada como tendo origem, em grande parte, no embate entre essas instâncias, ingrediente natural nas democracias.

Ao mesmo tempo, em âmbito interno, existem pressões para a manutenção das políticas mais restritivas e garantidoras da segurança e dos empregos nacionais, que visam manter os contingentes de migrantes indocumentados sem acesso aos sistemas de proteção social, como saúde e educação. Essa dinâmica pode ser identificada como a que opera nos jogos de dois níveis enunciados por Putnam (2010), em que se verifica: 1) o paradoxo pelo qual arranjos institucionais que fortalecem os tomadores de decisão no nível doméstico 
podem enfraquecer seu poder de barganha na arena internacional (e vice-versa); e 2) a potencial reverberação de pressões internacionais na agenda doméstica. Essa perspectiva contribuiria para explicar por que alguns compromissos internacionais têm impacto mais imediato na evolução da legislação e das políticas migratórias e outros não.

O presente artigo apresentou, portanto, as convergências e os distanciamentos existentes entre as políticas externa e migratória, a partir do mapeamento dos compromissos internacionais assumidos pelo Brasil e das percepções de atores envolvidos na execução de ambas as políticas, especialmente para o caso haitiano.

Foi possível observar a ambiguidade do comportamento do Estado brasileiro em relação ao tema das migrações internacionais, embasada, conforme a hipótese inicial, em redirecionamentos parciais da política externa brasileira face aos anseios do país na agenda internacional, porém, levando-se em conta os desafios internos.

Nesse sentido, o redirecionamento proposto não segue um padrão estabelecido por Hermann (1990), mas sim uma parcialidade no trato da questão migratória, na qual o governo brasileiro coordenou, no caso dos haitianos, uma posição altiva na MINUSTAH com uma tímida e conturbada reclassificação dos migrantes haitianos - desde a negação de pedidos de refúgio até a criação de um visto humanitário -, consolidando-se com a autorização de permanência final, um processo que perdurou durante cinco anos.

Em suma, observa-se tratativas fomentadas pela agência direta do Ministério da Justiça em coordenação com o Ministério das Relações Exteriores para a discussão e inclusão da política migratória dentro da formulação da Política Externa Brasileira, a exemplo de outros países, como Argentina e Canadá, isto é, vinculando diretamente os anseios de projeção externa do Brasil com situações-problema enfrentadas internamente, como o caso das migrações em massa, característica presente em todos os great powers.

\title{
THE CHANGE OF BRAZILIAN FOREIGN POLICY FOR IMMIGRANTS AND REFUGEES: THE CASE OF HAITIAN IMMIGRATION IN THE BEGINNING OF THE 21ST CENTURY
}

\begin{abstract}
With regard to the growing migration flow of Haitians towards the Brazilian territory, experienced specially after the year 2010, this article analyses the changes in the Brazilian foreign policy to immigrants and refugees, with special focus on this migratory group. The paper assumes that there had been a recategorization of these migrants, previously classified by the Brazilian government as refugees, with regard to the aspirations of international projection of the country. Such aspirations were crystallized under the action of Brazil in regional forums on migration and human rights issues, in charge of the United Nations
\end{abstract}


Stabilization Mission in Haiti and the permanent seat in the International Organization for Migration and United Nations High Commissioner for Refugees, perhaps, a step to the aims of the Brazilian state with the United Nations Security Council. Using the approaches of authors of the contemporary Brazilian Foreign Policy, this paper will highlight what were the sources of change suffered in the Brazilian foreign and migration policies, based on the case of the Haitians, which possibly is replicated to other relevant groups such as Syrians and Senegalese. Finally, the article points out the challenges and points of convergence between these two policies, in addition to the inconsistencies arising from domestic migration issues in addition to the foreign strategic insertion aspirations of the Brazilian government between 2010 and 2015.

Keywords: Immigration; Brazil; Foreign Policy; Haitians.

\section{Referências}

AGÊNCIA BRASIL. Governo concede autorização de permanência a 43,8 mil imigrantes haitianos. 2015. Disponível em: <http://agenciabrasil.ebc.com.br/geral/noticia/201511/ministros-assinam-ato-concedendo-autorizacao-de-permanencia-para-haitianos $>$. Acesso em: 18 nov. 2015.

ARCARAZO, Diego Acosta; WIESBROCK, Anja (Ed.). Global Migration: Old Assumptions, New Dynamics. Santa Barbara: Praeger, 2015. 3 v.

BRASIL. Ministério do Trabalho e Emprego. Conselho Nacional de Imigração (CNIg). Resolução Normativa 97/2012, 12 de janeiro de 2012. Disponível em: <http://www.veritae.com.br/lex-5110BF3C-850E57F3B739/2882_149_13-0112_trabalho.pdf >. Acesso em: 18 nov. 2015.

BRUNET, Roger; FERRAS, Robert; THÉRY, Hervé. Immigration. In: BRUNET, Roger; FERRAS, Robert; THÉRY, Hervé. Les mots de la Géographie. 3. ed. Paris: Reclus - La Documentation Française, 2012. p. 271.

BURGES, Sean W. Brazil as a bridge between old and new powers? International Affairs, [s.1.], v. 89, n. 3, p.577-594, maio 2013. Wiley-Blackwell. DOI: 10.1111/1468-2346.12034. Disponível em: <http://api.wiley.com/onlinelibrary/tdm/v1/articles/10.1111/14682346.12034>. Acesso em: 18 nov. 2015.

CERVO, Amado. Inserção Internacional: formação dos conceitos brasileiros. São Paulo: Saraiva, 2008. 297 p.

CHADE, Jamil. Peru admite pressão do Brasil para pedir visto a haitianos. Estadão, Internacional, 12 de jun. 2012. Disponível em:

$<$ http://internacional.estadao.com.br/noticias/geral,peru-admite-pressao-do-brasil-para-pedirvisto-a-haitianos-imp-,885077>. Acesso em 13 de nov. 2015.

CONECTAS DIREITOS HUMANOS. Governo fecha abrigo para haitianos em Brasileia. 2014. Disponível em: <http://www.conectas.org/pt/acoes/politica- 
externa/noticia/17008-governo-fecha-abrigo-para-haitianos-em-brasileia>. Acesso em: 28 nov. 2014.

DIAS, Carolina Sanches Lecornec et al. Política brasileira para refugiados: política de Estado ou política de governo?. Fronteira: revista de iniciação científica em Relações

Internacionais, v. 10, n. 19, p. 25-40, 2011.

DIZNER, Gabriel Felipe da Fonseca. Política externa e política migratória no Brasil: convergências e distanciamentos (1995-2010). 2015. 131 f. Dissertação (Mestrado) - Curso de Relações Internacionais, Universidade de Brasília, Brasília, 2015. Disponível em: <http://repositorio.unb.br/handle/10482/18282>. Acesso em: 18 nov. 2015.

FERNANDES, Duval et al. Migração dos Haitianos para o Brasil: a RN n o 97/2012: uma avaliação preliminar. Cadernos de Debates Refúgio, Migrações e Cidadania, Brasília, v. 8, n. 8, p.55-71, dez. 2013. Disponível em:

<https://haitianosnobrasil.files.wordpress.com/2015/05/caderno-debates-8.pdf >. Acesso em: 18 nov. 2015.

FARIA, Maria Rita Fontes. Migrações internacionais no plano multilateral: reflexões para a política externa brasileira. Brasília: FUNAG, 2015. 306 p. Disponível em:

$<$ http://funag.gov.br/loja/download/1130-

Migracoes_internacionais_no_plano_multilateral_23_10_2015.pdf >. Acesso em: 22 nov. 2015.

HATTON, Timothy J.; WILLIAMSON, Jeffrey G. The age of mass migration: causes and economic impact. New York: Oxford University Press, 1998. 301 p.

HERMANN, Charles F. Changing Course: When Governments Choose to Redirect Foreign Policy. International Studies Quarterly, [s.1.], v. 34, n. 1, p.3-21, mar. 1990. Disponível em: <http://www.voxprofessori.com/cfh/hermann-pubs/Hermann-Changing Course When Governments Choose to Redirect.pdf>. Acesso em: 24 set. 2015.

JACOBSEN, Karen. Factors influencing the policy responses of host governments to mass refugee influxes. International migration review, Nova York, v. 30, n.3, p. 655-678, 1996.

JUBILUT, Liliana Lyra. Refugee Law and Protection in Brazil: a model in South America? Journal of Refugee Studies. Oxford, v. 19, n. 1, p. 22-44, 2006.

JUBILUT, Liliana Lyra. O Direito internacional dos refugiados e sua aplicação no orçamento jurídico brasileiro. São Paulo: Método, 2007. 240 p. Disponível em: <http://www.pucpcaldas.br/uploads/59/03_Refugiados_e_sua_proteção_jur.pdf >. Acesso em: 18 nov. 2015.

KOROBKOV, Andrei V. The BRICS Members and the Migration Challenge. In: GLOBAL SOUTH INTERNATIONAL STUDIES CONFERENCE, 2., 2015, Singapura. Program. Singapura: GSCIS, 2015. p. 1 - 11. Disponível em: $<$ http://web.isanet.org/Web/Conferences/GSCIS Singapore 2015/Archive/8b92eef0-bdaf46c7-a4b7-95ce0f1237dd.pdf>. Acesso em: 18 nov. 2015. 
LEAL, Marília Daniella Freitas Oliveira; LEITE, Alexandre César Cunha. A Política Externa Brasileira e a questão dos deslocados ambientais: breves reflexões sobre a (des)proteção dos haitianos no Brasil. Revista de Estudos Internacionais, João Pessoa, v. 3, n. 2, p.47-58, 2012. Disponível em:

<http://www.revistadeestudosinternacionais.com/uepb/index.php/rei/article/viewFile/102/pdf >. Acesso em: 17 nov. 2015.

LIMA, Maria Regina Soares de; HIRST, Monica. Brazil as an intermediate state and regional power: action, choice and responsibilities. International Affairs, [s.1.], v. 82, n. 1, p.21-40, jan. 2006. Wiley-Blackwell. DOI: 10.1111/j.1468-2346.2006.00513.x. Disponível em: <http://api.wiley.com/onlinelibrary/tdm/v1/articles/10.1111/j.1468-2346.2006.00513.x>. Acesso em: 18 nov. 2015.

LOESCHER, Gil. Beyond Charity: international cooperation and the global refugee crisis. Nova York: Oxford University Press, 1996.

MINISTÉRIO DAS RELAÇÕES EXTERIORES. Missão de Estabilização das Nações Unidas no Haiti. 2016. Disponível em: <http://www.itamaraty.gov.br/pt-BR/politicaexterna/paz-e-seguranca-internacionais/142-minustah>. Acesso em: 16 jul. 2016.

MOREIRA, Julia Bertino. Política Externa e Refugiados no Brasil: uma análise sobre o governo Lula. In: ENCONTRO NACIONAL DA ABRI, 5., 2015, Belo Horizonte. Anais do $5^{\circ}$ Encontro Nacional da ABRI. Belo Horizonte: Abri, 2015. p. 1 - 16. Disponível em: $<$ http://www.encontronacional2015.abri.org.br/arquivo/downloadpublic?q=YToyOntzOjY6In BhcmFtcyI7czozNToiYToxOntzOjEwOiJJRF9BUlFVSVZPIjtzOjQ6IjQ3NDkiO30iO3M6M ToiaCI7czozMjoiMzE4N2Y1OTQ1ZjhhNjI0NTVjOTM2YWM5MmQzNzRkNDAiO30=>. Acesso em: 25 set. 2015.

ORGANIZAÇÃO INTERNACIONAL PARA AS MIGRAÇÕES. Perfil Migratório do Brasil 2009. Genebra: Organização Internacional Para As Migrações, 2009. 148 p. Disponível em: <http://www.mte.gov.br/trab_estrang/perfil_migratorio_2009.pdf>. Acesso em: 11 nov. 2014.

PATARRA, Neide Lopes (Coord.). Emigração e imigração internacionais no Brasil contemporâneo. São Paulo: Fundo de População das Nações Unidas, 1995. 200 p.

PIORE, Michael J. Birds of passage: migrant labor and industrial societies. Nova York: Cambridge University Press, 1979. 229 p.

PÓVOA NETO, Helion. O erguimento de barreiras à migração e a diferenciação dos "direitos à mobilidade". Revista Interdisciplinar da Mobilidade Humana, Brasília, v. 16, n. 31, p.394400, 2008. Disponível em:

<http://www.csem.org.br/remhu/index.php/remhu/article/view/121/113>. Acesso em: 18 nov. 2015.

PUTNAM, Robert D. Diplomacia e política doméstica: a lógica dos jogos de dois níveis. Rev. Sociol. Polit., Curitiba, v. 18, n. 36, p.147-174, jun. 2010. Disponível em:

<http://dx.doi.org/10.1590/S0104-44782010000200010>. Acesso em: 18 nov. 2015. 
REDIN, Giuliana; MINCHOLA, Luís Augusto Bittencourt (Org.). Imigrantes no Brasil: Proteção de Direitos Humanos e Perspectivas Político-Jurídicas. Curitiba: Juruá Editora, 2015. $1 \mathrm{v}$.

REIS, Rossana Rocha. A política do Brasil para as migrações internacionais. Contexto Internacional, Rio de Janeiro, v. 33, n. 1, p.47-69, jun. 2011. Disponível em:

<http://dx.doi.org/10.1590/S0102-85292011000100003>. Acesso em: 17 nov. 2015.

ROCHA-TRINDADE, Maria Beatriz da. Sociologia das Migrações. Lisboa: Universidade Aberta, 1995. $410 \mathrm{p}$.

RODRIGUES, Gilberto Marcos Antonio. O futuro do refúgio no Brasil e seu papel no cenário humanitário. In: BARRETO, Luiz Paulo Teles Ferreira (Org.). Refúgio no Brasil: a proteção brasileira aos refugiados e seu impacto nas Américas. Brasília: Acnur, 2010. Cap. 6. p. 132149. Disponível em:

<http://www.acnur.org/t3/fileadmin/Documentos/portugues/Publicacoes/2010/Refugio_no_Br asil.pdf?view=1>. Acesso em: 16 nov. 2015.

RÜCKERT, Aldomar Arnaldo. Enquanto a União Europeia comemora sua nova política regional refugiados batem à sua porta. Confins, Paris, n. 25, nov. 2015. Disponível em: <https://confins.revues.org/10596?lang=pt>. Acesso em: 16 jul. 2016.

SANTOS, Fernando Damazio dos. Imigração Haitiana ao Brasil: Especificidades e Dispositivo de Política Migratória Empregado pelo Estado Brasileiro. 2014. 84 f. TCC (Graduação) - Curso de Relações Internacionais, Universidade Federal de Santa Catarina, Florianópolis, 2014. Disponível em: 〈https://repositorio.ufsc.br/handle/123456789/128079>. Acesso em: 17 nov. 2015.

SARAIVA, Miriam Gomes. Balanço da política externa de Dilma Rousseff: perspectivas futuras? Relações Internacionais, Lisboa, n. 44, dez. 2014. Disponível em:

<http://www.scielo.mec.pt/scielo.php?script=sci_arttext\&pid=S1645-

91992014000400003\&lng=pt\&nrm=iso $>$. Acesso em: 24 set. 2015.

SEITENFUS, Ricardo. Elementos para uma diplomacia solidária: a crise haitiana e os desafios da ordem internacional contemporânea. [20--]. Disponível em:

$<$ http://www.seitenfus.com.br/arquivos/elementos-diplomacia(1).pdf>. Acesso em: 17 nov. 2015.

SICILIANO, André Luiz. A Política Migratória Brasileira: Limites e Desafios. São Paulo: IRI/USP, 2013. Dissertação (Mestrado em Relações Internacionais) - Instituto de Relações Internacionais, Universidade de São Paulo. Disponível em:

<http://www.iri.usp.br/documentos/defesa_12-04-19_Andre_Luiz_Siciliano.pdf >. Acesso em 20 nov. 2015.

SILVA, César Augusto Silva da. Política migratória brasileira para refugiados (1998-2014). Curitiba: Íthala, 2015. 312 p.

SOUZA, Amaury de. A agenda internacional do Brasil: a política externa brasileira de FHC a Lula. Rio de Janeiro: Elsevier; CEBRI, 2009. 
TEITELBAUM, Michael. Immigration, Refugees and foreign policy. International Organization, v. 38, n. 3, p.429-450, 1984.

UEBEL, Roberto Rodolfo Georg. Análise do perfil socioespacial das migrações internacionais para o Rio Grande do Sul no início do século XXI: redes, atores e cenários da imigração haitiana e senegalesa. 2015a. 248 f. Dissertação (Mestrado) - Programa de PósGraduação em Geografia, Universidade Federal do Rio Grande do Sul, Porto Alegre, 2015. Disponível em: <http://hdl.handle.net/10183/117357>. Acesso em: 27 out. 2015.

UEBEL, Roberto Rodolfo Georg. O Brasil na agenda global das migrações internacionais: inserção estratégica ou ciclos migratórios?. In: SEMINÁRIO INTERNACIONAL DE CIÊNCIA POLÍTICA, 1., 2015, Porto Alegre. Anais do $1^{\circ}$ Seminário Internacional de Ciência Política. Porto Alegre: UFRGS, 2015b. p. 1 - 25. Disponível em: $<$ http://www.ufrgs.br/sicp/files/2015/09/UEBEL-2015-O-Brasil-na-agenda-global-dasmigrações-internacionais.pdf >. Acesso em: 25 out. 2015.

UNIÃO DE NAÇÕES SUL-AMERICANAS. Objetivos específicos. 2008. Disponível em: <http://www.unasursg.org/es/objetivos-especificos>. Acesso em: 16 jul. 2016.

VALLER FILHO, Wladimir. O Brasil e a crise haitiana: a cooperação técnica como instrumento de solidariedade e de ação diplomática. Brasília: FUNAG, 2007. 396 p.

VENTURA, Deisy (Ed.). Anteprojeto de Lei de Migrações e Promoção dos Direitos dos Imigrantes no Brasil. Brasília: Ministério da Justiça, 2014. 52 p. Disponível em: <https://saudeglobaldotorg1.files.wordpress.com/2014/08/anteprojeto_v-final-1.pdf>. Acesso em: 18 nov. 2015.

VENTURA, Deisy; ILLES, Paulo. Qual a política migratória do Brasil?. Le Monde Diplomatique, São Paulo, 7 de mar. 2012. Disponível em:

<http://www.diplomatique.org.br/artigo.php?id=1121>. Acesso em 17 de nov. 2015.

VIGEVANI, Tullo; CEPALUNI, Gabriel. A política externa de Lula da Silva: a estratégia da autonomia pela diversificação. Contexto Internacional, [s.1.], v. 29, n. 2, p.273-335, 2007.

Disponível em: <http://www.scielo.br/scielo.php?script=sci_arttext\&pid=S0102-

$85292007000200002>$. Acesso em: 24 set. 2015.

ZOLBERG, Aristide; SUHRKE, Astri; AGUAYO, Sergio. International Factors in the Formation of Refugee Movements. In: COHEN, Robin (Ed.). Theories of Migration. Cheltenham; Brookfield: Elgar Reference Collection, 1996. p. 312-330.

\section{Sobre o autor:}

Roberto Rodolfo Georg Uebel é Doutorando do Programa de Pós-Graduação em Estudos Estratégicos Internacionais da Universidade Federal do Rio Grande do Sul e Pesquisador do Laboratório de Estudos Internacionais (LEIn/UFSM), Laboratório Estado e Território (LABETER/UFRGS) e CESPRI - Grupo de Pesquisa em Cultura Política, Estado e Relações Internacionais (UFRGS). Endereço Eletrônico: roberto.uebel@ufrgs.br. 